\title{
ASCARIS LUMBROCOIDES IN THE RIGHT MAXILLARY SINUS-A RARE CASE
}

\author{
SAHA KL ${ }^{1}$, RASHID $\mathrm{MS}^{2}$, JAMTSHO $\mathrm{S}^{3}$, TALUKDER DC ${ }^{4}$
}

\begin{abstract}
:
Introduction: Sinusitis is fairly a common condition in an Otolaryngology clinic. However sinusitis due to Ascaris lumbrocoides obstructing the maxillary ostium is a very rare case.

Objective: To report a very rare case of round worm in the Right Maxillary sinus.

Case report: A nine year old girl presented with right nasal blockage and dull aching pain over the right maxilla and foul smelling discharge from the right nostril for a week duration. Examination revealed a cord like structure in the right nostril which was very painful on manipulation. Examination under generl anesthesia revealed a $15 \mathrm{~cm}$ long dead Ascaris lumbrocoides in the right nostril emerging from the right maxillary sinus obstructing its ostium. After removal of the round worm, patient and the immediate family members were treated with Albendazole.
\end{abstract}

Conclusion: In rare occasions, particularly in underdeveloped countries, clinicains should be midful that round worms can be a cause of sinusitis.

Key words: Ascaris lumbrocoides, maxillary sinus, sinusitis, endoparasites

J Dhaka Med Coll. 2019; 28(1) : $126-128$

\section{Introduction:}

Round worms are caused by intestinal nematodes known as Ascaris lumbrocoides. Ascaris lumbricoides is one of the most familiar endoparasites of man. It has also been reported from sheep, pigs, cattle etc. It inhabits the small intestine, more frequently of children than of adults, where it is supposed to feed on the semi digested food of the host. ${ }^{1}$

Ascaris lumbrocoides requires only one host to complete its life cycle and no intermediate host is required. Man is the only known definitive host of Ascaris lumbricoides ${ }^{2,3}$ The infection occurs by ingestion of food contaminated with infective eggs which hatch in the upper small intestine. The larvae ( $250 \times 15$ micrometers) penetrate the intestinal wall and enter the venules or a fertilized Ascaris egg, still at the unicellular stage, as they are when passed in stool. Eggs are normally at this stage when passed in the stool. The larvae pass through the liver, heart and lung to reach alveoli in 1 to 7 days during which period they grow to 1.5 $\mathrm{cm}$. They migrate up the bronchi, ascend the trachea to the glottis, and pass down the esophagus to the small intestine where they mature in 2 to 3 months. A female may live in the intestine for 12 to 18 months and has a capacity of producing 25 million eggs at an average daily output of $200,000.4^{4,5}$

The annual global morbidity due to ascaris infections is estimated at 1 billion with a mortality of 20,000. Ascariasis can occur at all ages, but it is more prevalent in the 5 to 9 years age group. It is common disease in Indian subcontinent and more so in poor rural populations. ${ }^{1,2,5}$

Although Ascariasis is common in gastrointestinal tract, presence of it in the maxillary sinus causing sinusitis is extremely rare. Literature review found that only one case of

1. Dr. Kanu Lal Saha, Associate Professor, Department of Otolaryngology and Head-Neck Surgery, Bangabandhu Sheikh Mujib Medical University, Dhaka, Bangladesh.

2. Dr. Md Sajibur Rashid, Associate Professor, Department of Otolaryngology and Head-Neck Surgery, Cumilla Medical College Hospital, Cumilla, Bangladesh

3. Dr Sonam Jamtsho, ENT surgeon, Jigme Dorji Wangchuk National Referral Hospital, Bhutan.

4. Dr. Debesh Chandra Talukder, Associate Professor, Department of Otolaryngology and Head-Neck Surgery, Dhaka Medical College Hospital, Dhaka, Bangladesh

Correspondence: Dr. Kanu Lal Saha, Associate Professor, Department of Otolaryngology and Head-Neck Surgery, Bangabandhu Sheikh Mujib Medical University, Dhaka, Bangladesh, Room no.702, Block-C ,BSMMU, Email:drklsaha@gmail.com 
Ascaris lumbrocoides in the nose in a14 year old girl was reported by Prof H. Burger in $1918^{6}$. Herein, we report another case of an Ascaris lumbrocoides located in the right maxillary sinus.

\section{Case Presentation}

A 9-years-old girl with low socioeconomic status presented in Department of Otolaryngology, Bangabandhu Sheikh Mujib Medical University, Dhaka with a 7 -days history of dull aching pain on the right side of the nose, spreading over the maxillary sinus area, and on the infra-orbital margin on the same side associated with foul smelling nasal discharge from the right nostril. She also had blockage of right nostril but no history of blood stained discharge or epistaxis. Few days after the discomfort she had noticed a cord like structure in her right nostril but no sense of movement was felt. Her medical history and the family history were non-contributory.

General examination revealed that the patient was conscious and co-operative, with a normal IQ. She was mildly anemic. On examination of nose, a cord like structure was seen in the right nasal cavity. The cord like structure seemed to be connected with middle meatus of right nasal cavity. Gentle traction on it patient complained of severe pain. It reached up to anterior nares. Color of the round cord like structure was pale. The lateral aspects of the nose, maxillary sinus area and infra-orbital margin were tender on the right side. No lymphadenopathy was noted. Intra-oral examination revealed no other significant finding.

On radiographic examination the right sided maxillary sinus was found hazy and the rest of paranasal sinuses was clear (figure 1). Since it was very painful, decision was taken to examine and manage the patient under general anesthesia.

With endotracheal intubation nasal cavity was examined and the cord like structure was extending to the middle meatus and entering into the ostium into the antrum of right maxillary sinus. Antral washing trocar and cannula is introduced through the inferior meatus. Gentle traction on the cord and forceful irrigation of sinus with normal saline through cannula a long cord like structure come out from maxillary sinus.

On close and detailed observation of whole structure it was detected as a long round warm and died on entrapment at maxillary antrum three to four days back. It is $15 \mathrm{~cm}$ long. (Figure 2.) A thick pus like collection was noted coming out from the maxillary ostium. After thorough irrigation, no other round worms were found in the maxillary antrum.

Patient recovered fully and she and all her immediate family members were given anthelminthic treatment with albendazole. They were advised for improvement of general hygiene, safe practices of cooking and to avoid open defecation.

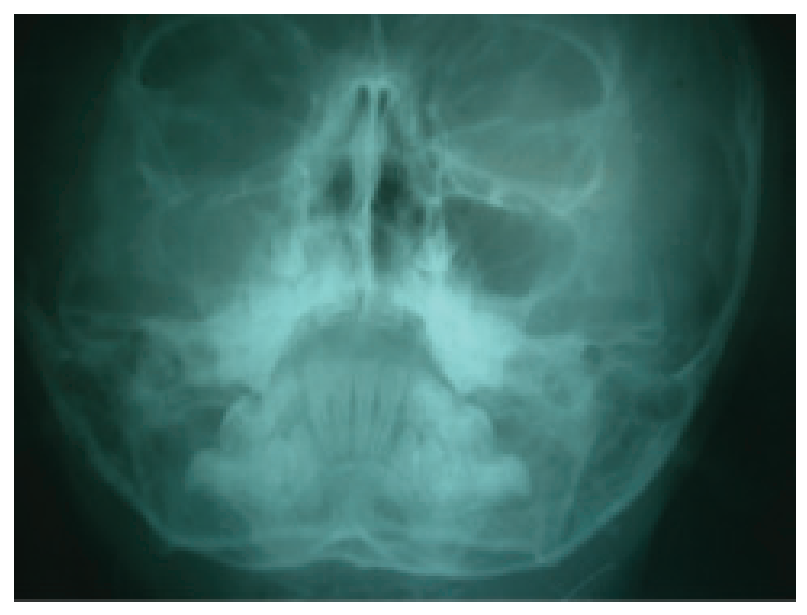

Fig.-1: X ray PNS OM view showing haziness in the right maxillary sinus.

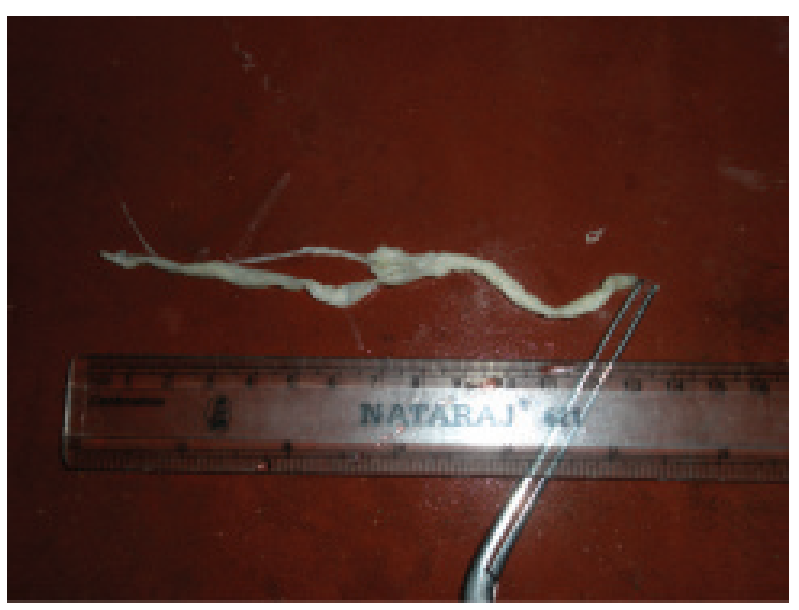

Fig.-2: Dead Ascaris lumbrocoides after removal 


\section{Discussion:}

Round worm infestation of the maxillary sinus is extremely rare. Besides the first case reported by Prof $\mathrm{H}$. Burger, another case was reported by Naravene et al in 1997 which was found during a routine sagittal section of head neck region, where they found 3 mature Ascaris lumbrocoides in maxillary sinus and 3 in the sphenoid sinus. ${ }^{7}$ Oschner et a. described a case of sudden suffocation from the impaction of Ascaris in the larynx. ${ }^{8}$ Detail movement of Ascaris was described by Makidono when he published his observations on Ascaris under Fluoroscopy. Makidono noted that if the head of an Ascaris engages in an orifice this will act as a powerful stimulus causing the worm to make its way into the orifice and to advance into any channel leading off from it. ${ }^{9}$ Therefore the emergence of an Ascaris from the nostril could be the result of the head of an Ascaris entering the nostril and thereby being stimulated to emerge from the nostril. This unheralded occurrence shows that the round worm have reached and remained in the nasal passage without giving any hint of their presence there. So in this case, the round worm might have migrated to the nasal cavity and then to the maxillary sinus by its own muscular movement without the notice of the host. However, with the growth in size and the relatively limited space of the maxillary sinus the worm might have tried get out of the maxillary ostium thus blocking the maxillary sinus drainage and causing all the clinical features of sinusitis and getting itself killed due to entrapment. Other mechanism could be during the hepato tracheal migration of the the Ascaris larvae, it could have been coughed up during Loffler's pneumonitis and got deposited in the maxillary sinus. ${ }^{1,4,5,8,10}$

\section{Conclusion:}

Ascaris lumbrocoides usually infests in the gastrointestinal tract. But on rare occasions, it can ascend further up from its usual migration route and lie in maxillary sinus causing sinusitis. Therefore such cases need surgical removal of the worm and also instituting medical treatment with antihelmenthetic, albendazole or mebendazole to the patient to ensure that all the worms in the body is treated. Also it is of paramount importance to treat the immediate family members with antihelmenthetics to prevent cross fecoral transmission of the worms and educate the family on the importance of toilets and hang hygiene.

\section{References}

1. Khuroo MS. Ascariasis. Gastroenterology Clinics of North America. 1996 Sep 1;25(3):553-77.

2. Pawlowski ZS, World Health Organization. Intestinal helminthiases and human health: recent advances and future needs. Geneva: World Health Organization; 1986.

3. Crompton DW. The prevalence of ascariasis. Parasitology today 1988 Jun 1; 4(6):162-9.

4. Dold C, Holland CV. Ascaris and ascariasis. Microbes and infection2011 Jul 1; 13(7):632-7.

5. Crompton DW. Ascaris and ascariasis.2001: 285-375.

6. Burger H. Ascaris lumbricoides in the nose. Acta OtoLaryngologica1922 Jan 1; 4(1):63-5.

7. Naravane A, Lindo JF, Williams LA, Gardner M, Fletcher CK. Ascaris lumbricoides in the paranasal sinuses of a Jamaican adult. Trans R Soc Trop Med Hyg 1997; 91(1):37.

8. Ochsner A, DeBAKEY EG, DIXON JL. Complications of Ascariasis Requiring Surgical Treatment: Report of Case with Abdominothoracic Complications. American Journal of Diseases of Children 1949 Mar 1; 77(3):389-407.

9. Makidono J. Observations on Ascaris during fluoroscopy. The American journal of tropical medicine and hygiene 1956 Jul 1; 5(4):699-702.

10. Paul M. The movements of the adult Ascaris lumbricoides. British Journal of Surgery 1972 Jun; 59(6):437-42. 